\title{
Determinants of Adherence to Antiretroviral Therapy among HIV-Infected Patients in Africa
}

\author{
Ayalu A. Reda ${ }^{1}$ and Sibhatu Biadgilign ${ }^{2}$ \\ ${ }^{1}$ Department of Public Health, College of Health Sciences, Haramaya University, P.O. Box 1014, Harar, Ethiopia \\ ${ }^{2}$ Department of Epidemiology and Biostatistics, Jimma University, P.O. Box 24414, Jimma, Ethiopia
}

Correspondence should be addressed to Sibhatu Biadgilign, sibhatu2005@yahoo.com

Received 15 October 2011; Accepted 15 December 2011

Academic Editor: Gene D. Morse

Copyright () 2012 A. A. Reda and S. Biadgilign. This is an open access article distributed under the Creative Commons Attribution License, which permits unrestricted use, distribution, and reproduction in any medium, provided the original work is properly cited.

Background. There are only a few comprehensive studies of adherence to ART and its challenges in Africa. This paper aims to assess the evidence on the challenges and prospects of ART adherence in sub-Saharan Africa. Methods. The authors reviewed original and review articles involving HIV-positive individuals that measured adherence to ART and its predictors in the past decade. Findings. Against expectations, sub-Saharan Africa patients have similar or higher adherence levels compared to those of developed countries. The challenges to ART adherence include factors related to patients and their families, socioeconomic factors, medication, and healthcare systems. Conclusion. Despite good adherence and program-related findings, antiretroviral treatment is challenged by a range of hierarchical and interrelated factors. There is substantial room for improvement of ART programs in sub-Sahara African countries.

\section{Introduction}

Acquired immune deficiency syndrome (AIDS) is one of the most destructive epidemics the world has ever witnessed. Presently an estimated 33.4 million people are living with HIV worldwide, nearly two-thirds of these live in subSaharan Africa [1].

Antiretroviral therapy (ART) has shown to delay progression to AIDS, resulting in a greater and more sustained virologic and immunologic response [2] and improve survival [3]. In sub-Saharan Africa, there has been a dramatic increase in the number of HIV/AIDS patients on antiretroviral treatment from just 100,000 persons in 2003 to 3.9 million in 2009 involving close to $40 \%$ of those in need of the treatment [4]. Two sub-Saharan Africa countries, Botswana and Rwanda, have achieved universal access target (treatment coverage of $80 \%$ or more of patients in need) at the end of 2009 [4], while countries such as Ethiopia, Zambia, Namibia, and Senegal are moving closer to the same target having covered $50-80 \%$ of patients in need of treatment [4].

According to recent studies, ART regimens require 70$90 \%$ adherence in order to be effective [5]. However, sustaining adherence to antiretroviral therapy (ART) over the long term requires accurate and consistent monitoring, and this is a particular challenge for countries in sub-Saharan Africa [5]. It is further challenged by various social and clinical obstacles [5] where inadequate suppression of viral replication by ART are resulting due to poor adherence to therapy, low potency of the antiretroviral regimens, viral resistance to antiretroviral medications, and pharmacokinetic interactions [6] causing inadequate drug delivery $[5,7]$. The transmissibility of the antiretroviral resistant viruses from person to person further compounds the problem as a clinical and public health challenge $[8,9]$.

Adherence is defined as taking medications or interventions correctly according to prescription. There are different methods for assessing adherence and the level of adherence is specific not only to places and patient groups but also to the method of adherence measurement used [10]. They include direct methods such as biologic markers and body fluid assays, or indirect methods such as self-report, interview, pill counts, pharmacy records, computerized medication caps, and viral load monitoring. While a combination of these methods may be employed, patient self-report is the most widely used [11] given its ease of implementation and use of already existing resources. Studies have also 
indicated that self-reports correlate well with both viral load and clinical outcomes [12, 13]. Use of computerized medication caps and monitoring of surrogate markers seems reliable and less prone to respondent bias. However, the advanced technology, high cost, and logistic requirements have precluded their wider application in sub-Saharan Africa [14]. In developing countries, pharmacy refill reports and self-reports are commonly implemented for adults [5, 15], while caregiver reports are employed for children $[11,16$, 17]. Currently, there are no gold standard methods for measuring adherence [5].

There are only very few studies that investigate adherence to ART in sub-Saharan Africa. The aim of this paper is to assess the challenges of adherence to ART and to identify the factors that contribute to poor adherence.

1.1. Current Estimates of Adherence. Studies indicate that despite earlier fears of poor medication adherence [6, 18], patients in developing countries are able to achieve adherence levels similar to or higher than those of patients in developed countries [19]. For instance, a review by Vreeman and colleagues indicated that the majority of the studies in developing countries report adherence levels of more than 75\% (range 45-100\%) [11], while in developed countries the majority report less than 75\% (range 20-100\%) [17]. Another systematic review by Mills and colleagues obtained a pooled estimate of adequate adherence by sub-Saharan Africa patients of $77 \%$ (95\% confidence interval, 68-85\%; based on a total of 12,116 patients), whereas the figure for North American patients was 55\% (95\% confidence interval 49-62\%; based on a total of 17,573 patients) [20]. The same study concluded that adherence is a concern in North America.

1.2. Patient-and Family-Related Challenges. With regard to children, if the mother (or other caregiver) is infected, then she is struggling with her own illness, psychosocial factors, medication regimens, and most often financial burden due to expenses incurred on her own therapy, child's therapy, and associated cost of medical treatment [21, 22]. All of these produce negative influences on adherence. Empirical evidence increasingly suggest that user fees in some centers for antiretroviral therapy (ART) and HIV/AIDS care decrease adherence $[23,24]$. These factors on top of the caregivers' and patients' experience, knowledge and beliefs on ART [25], reduce the caregiver's ability to provide proper care to the child, thereby affecting the necessary adherence over time [26-31]. Furthermore, factors such as age (especially infancy and adolescence have a negative effect) [19], refusal of treatment, knowledge of HIV status, clinical stage, and depressive symptoms, male gender, and changes in health status (improvement as well as deterioration) have also been identified as important factors which affect adherence to HAART (highly active antiretroviral treatment) in pediatric patients $[22,27-30,32]$. Denial and fear of HIV status, misinformation, and misconceptions about HIV (for instance beliefs that ART cures HIV [16]), low availability, accessibility, and acceptance of therapy are some of the obstacles among HIV-infected adolescents.
It is known that mothers tend to hide HIV infection status from their children and disclosure is often delayed until adolescence [33]. Reddi and colleagues show that only $7.9 \%$ children had been made aware of their own HIV infection status in their study in South Africa [34]. Disclosure of HIV infection status is a critical step and has obvious implications for adherence. Starting the disclosure process as early as 8-9 years of age and combining it with specific support, as suggested (http://www.hivatis.org) may result in increased adherence in children. There are similar reports that indicate lack of disclosure as predictors of poor adherence in adults [35]. Self-perceived family support and/or the family's and the household's knowledge of the patient's HIV infection status are considered important predictors of adherence [36].

1.3. Stigma- and Discrimination-Related Challenges. Stigma, on top of the general knowledge of the population about HIV/AIDS and ART treatment, is an important determinant of adherence in the settings of sub-Saharan countries according to studies conducted recently [17, 37-39].

Social or family stigmatization and fear of the consequences of revealing HIV infection status to sexual partners are closely related to poor adherence [40]. Family plays a crucial role in any kind of treatment in children [41] or adults [42]. Major issues related to family or caregiver that influence adherence include presence of anxiety; depression $[37,43,44]$; active substance abuse [37]; the presence of HIV infection in another family member; fear of disclosure of HIV positivity to the family; family disruptions; belonging to racial minorities or other vulnerable groups of the population.

Family and community members can both play a positive and negative roles in ART treatment initiation and adherence $[42,45]$. For instance, the stigma associated with HIV infection or AIDS may be more severe than that of other illnesses, creating barriers to treatment initiation and support for adherence that might otherwise be available [42, 46]. On the positive side, family members and friends can play the role of treatment partners and provide much needed support [39, 42, 47].

Patients need to be encouraged by health care workers to disclose their status. However, studies of interventions to facilitate disclosure are lacking. Social institutions like the church, nongovernmental organizations (NGOs), and food aid services play a crucial role in issues ranging from creating awareness about the illness, mobilizing support, facilitating treatment, and promoting adherence $[16,42$, 48]. For instance, in an evaluation program about the impact of family nutritional support during the first year of antiretroviral treatment in the west Africa region, family nutritional support for persons living with HIV initiating antiretroviral treatment showed a positive impact after six months [49].

1.4. Substance-Abuse-Related Challenges. Drug abuse and alcohol consumption are factors that further threaten proper adherences to ART. Studies have consistently shown that 
active alcohol use and substance abuse makes it more difficult for patients to adhere to treatment [50-53]. For instance, in Botswana nearly 40 percent of the patients surveyed admitted missing a dose because of alcohol consumption [46]. Similar studies also indicate that alcohol is highly related to reduced adherence [54]. A systematic review in 2009 found that HIV/AIDS patients that used alcohol are 50-60\% more likely to adhere less to their prescribed medications [55].

1.5. Socioeconomic Challenges. The patterns of infection have been shown to vary globally depending on the social and economic conditions of the country affected, with poverty having a significant role as a social determinant of HIV/AIDS and the spread of the virus as well as access and adherence to ART treatment $[42,56]$.

Common reasons reported for missed doses include financial trouble $[38,57]$ that prevent caregivers of children or adult patients from collecting medication on time [42], distance barrier or lack of transportation facilities to the ART clinic [37, 46], vomiting of medication without redosing, incorrect dosing by a caregiver, missed clinic appointments and pharmacy collections, confusion between multiple caregivers, and self-discontinuation or refusal by children $[34,58,59]$. Furthermore, patients' beliefs that medications need to be taken with food leads them to avoid taking medications whenever food is unavailable, interfering with adherence $[42,60]$. Sometimes patients are forced to choose between paying for transportation to the ART facility and using the money for food [42, 57, 61]. Studies in Uganda and Tanzania reported that transportation costs are considered serious obstacles to taking ART $[62,63]$. This has implications not only for day-to-day adherence but also losses to follow up [64]. Determinants of ART adherence for HIV-infected persons in sub-Saharan Africa were examined with ethnographic research methods at HIV treatment sites in Jos, Nigeria, Dar es Salaam, Tanzania, and Mbarara, Uganda. The findings indicate that individuals taking ART routinely overcome economic obstacles to ART adherence through a number of deliberate strategies aimed at prioritizing adherence: borrowing and "begging" transport funds, making "impossible choices" to allocate resources in favor of treatment, and "doing without" [65].

1.6. Medication-Related Challenges. Good adherence (i.e., more than 95\%) was associated with beliefs regarding the positive impact of the medications on participants' quality of life. Characteristics of the commercially available drug formulations such as taste, palatability, size of pills, availability of liquid formulations, and adverse effects (e.g., metabolic complications, lipodystrophy) can significantly affect adherence. Furthermore, the complicated regimen [66] to be followed, such as the need for daily administration, dietary restriction, drug interactions, frequency of dosing, dosage, and therefore pill burden or amount of liquid, also influence child's adherence to therapy $[26,28,31,32,56]$. The above-mentioned medication-related factors are crucial in determining children's adherence to ART.

Chesney [27] reported that factors associated with nonadherence included housing instability and length of treatment with antiretroviral therapy. According to a report by Van Dyke et al. [67], the main reasons mentioned by patients for nonadherence were taste $(16 \%)$ and child refusal $(16 \%)$ for ritonavir, and taste $(9 \%)$ and interference of medication schedule with lifestyle $(10 \%)$ for nelfinavir [67]. Side effects are also usually associated with irregular medication intake or stopping medication altogether.

1.7. Health-Care- and Systems-Related Challenges. Structural factors not directly related to patient or medications can also influence adherence. Some researchers have even contended that these could be the most important barriers to ART adherence in resource limited settings [5]. Limited availability and accessibility of antiretroviral medications and healthcare facilities for diagnosis and treatment of HIV/AIDs, out-of-pocket payments, high cost of ART and other health services, presence of healthcare providers experienced in ART provision, patient-nurse and other provider relationships, health care providers' beliefs, waiting time and opening hours $[16,42,59,68-70]$, availability of counseling services, and social, economic, or psychological support for people living in both developing as well as developed countries can influence adherence positively or negatively [28]. Ensuring the privacy of ART clinics and waiting areas need to be given special emphasis as authors of this paper and others documented [16, 42]. For instance, Skovdal and colleagues reported about patients who refused to leave consultation rooms citing to nurses $\mathrm{Mr}$. so and so is outside [42].

Adherence support and clinic policies are also important predictors of adherence [37] as well as lack of adherence monitoring mechanisms [10]. A recent study from South Africa indicates that improving adherence is cost effective and helps to reduce health care costs especially those of hospital care [71].

1.8. Interventions to Improve Adherence. Continuous monitoring of both adherence and correlating it with clinical outcomes will create an interactive feedback mechanism that could lead to optimal clinical states and improved quality of life for patients. There are needs for further research and development in the area of ART adherence, adherence support, and patient behavior.

Diagnosing and treating health problems such as depression, reducing substance abuse, improving patient and provider relationship, counseling and enhancing family, and community support mechanisms are shown to improve adherence, as well as intervening on modifiable barriers to adherence before starting ART [72, 73]. A meta-analysis by Amico and colleagues indicated that adherence interventions may be efficacious when targeted at individuals who are identified or anticipated to have poor adherence [74].

The few investigations of interventions indicate that electronic reminders, pill organizers, medication-event monitoring systems (MEMS) to record dosing behavior, use of internet, educations services, use of phones [75], and so forth can also enhance adherence. However, most of these technologies have not had thorough scientific evaluation and their efficacy and cost effectiveness may not be as high as 


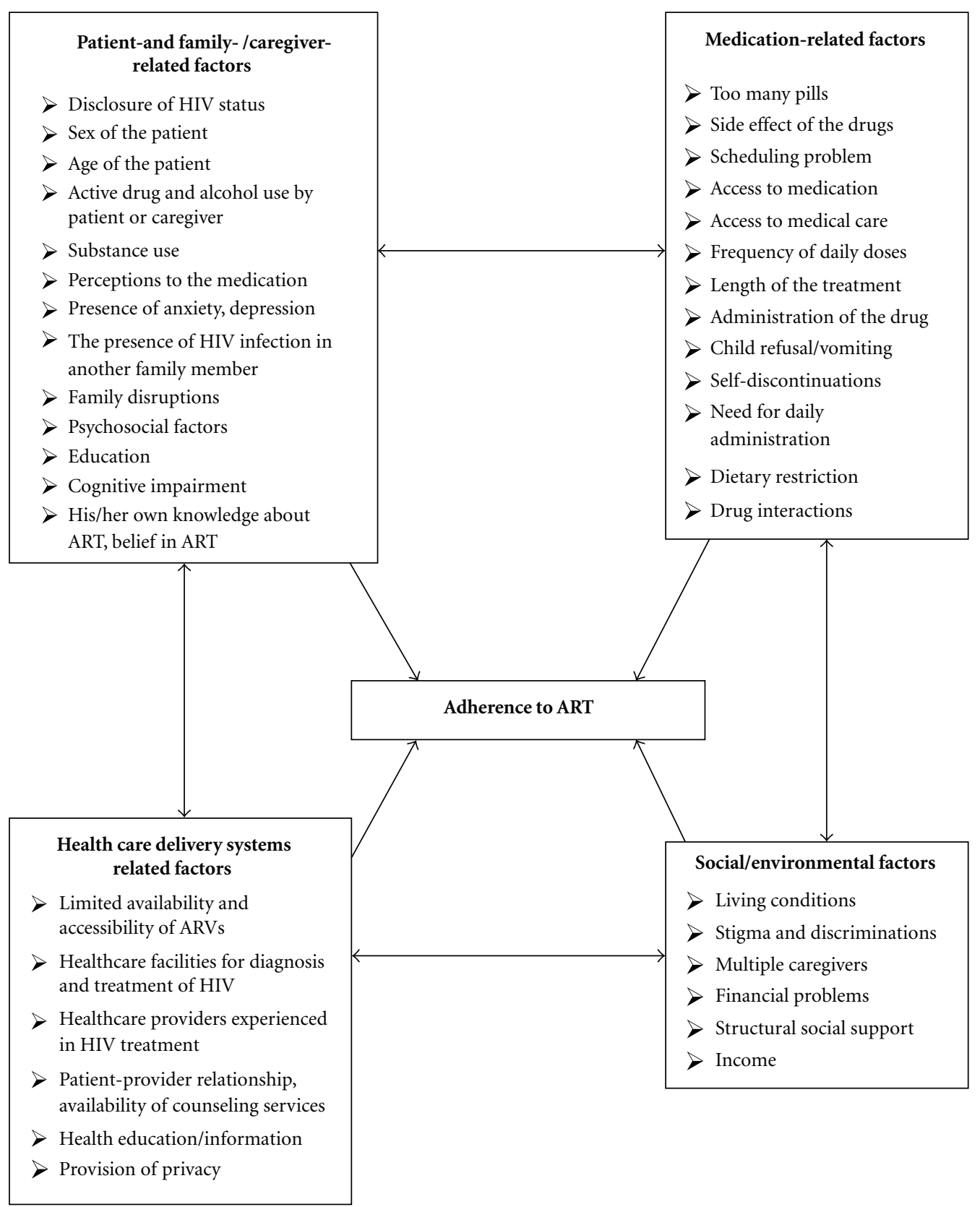

FIGURE 1: Identified factors for the challenges of adherence to ART.

expectations $[5,72,76]$. Cell phone message reminders and web-based interventions require patient resources and literacy which could create obstacles to their applicability in subSaharan Africa. A recent systematic review published by the Cochrane Database of Systematic Reviews reached similar conclusions. It cited diverse methodological problems and issues of study quality, among others as problems underlying the scant evidence on adherence improvement interventions and called for standardized and methodologically rigorous trials of interventions to improve and measure adherence to antiretroviral treatment [77].

\section{Discussion}

African HIV/AIDS patients have similar or higher adherence levels compared to those of developed countries. The challenges of adherence to ART identified include factors related to patients and their families, socioeconomic factors, medication, and healthcare systems as summarized in Figure 1. This has implications for interventions to improve ART adherence and therefore the program needs to address these interrelated and multidimensional factors $[78,79]$. In other words, ensuring adherence to treatment 
and retention requires an understanding of the multiple barriers that patients face and developing interventions that overcome these barriers. Long-term maintenance of adherence requires the integration of these interventions into sustainable programs that ensure a reliable supply of drugs, patient education, and ongoing support [80].

Low adherence to treatment has been associated with higher hospitalization rates, productivity loss, disease progression, and death in both high-income and resourcelimited settings [35]. It is clear that adherence problems can constitute a significant barrier to ART programs in African countries or elsewhere. Without regulated access to ART, rapid emergence of drug-resistant viral strains and individual treatment failure is a potential threat and could curtail future treatment options and leading to the transmission of drug resistant strains of HIV [18]. We have identified that in order to increase adherence to the appropriate level there needs to be concerted efforts to evaluate and conduct operational research on ART service provision. These include use of new monitoring mechanisms, infrastructure, staffing, training of counselors, community support systems, and suitable drug formulations [78]. But currently there are several research gaps such as lack of capacity to survey the level of drug resistance in sub-Saharan Africa and testing of new tools for monitoring adherence.

This paper mainly focused on studies conducted on African HIV/AIDS patients. As a result, the predictors of ART adherence identified in the review may not necessarily be applicable to countries outside the region. Furthermore, currently there is no gold standard for measuring adherence. Because of this, most of the studies included used the most common forms of adherence assessment-patient recall and pill count - which have recognized biases. These include over reporting, recall, and social desirability bias [81-83]. We measured influential factors for short-term to medium-term adherence and that our conclusions on these factors may not necessarily be extrapolated to losses to follow up or retention to ART programs.

Health system barriers affect adherence, especially a regular and timely supply of medication to patients. An unreliable supply of medications can severely reduce patient adherence rates. In the majority of the sub-Sahara Africa countries they are manifested by weak procurement and supply management systems that lead to frequent shortages of ART and other essential inputs. In a survey of 91 low- and middle-income countries in 2008, 34\% had experienced at least one stock out of a required ART medication [4].

In the future, it is possible that the encouraging trend of increased access to ART access may be further scaled up if governments and donors continue their commitment to the program. However, it is important that national governments take an increasing role in the program in order to make it sustainable. These include channeling of funds and policy commitments toward evaluation and improvement of the program. These also call for scale up of efforts to prevent the virus. In addition, policy measures to improve the socioeconomic status and empowerment of their citizens in general are very important.

\section{Conclusion and Recommendations}

There is a relatively modest level of adherence to antiretroviral treatment among HIV/AIDS patients in sub-Saharan Africa. However, it is challenged by a range of hierarchical and intricately related factors and there is substantial room for improvement of the ART programs in the region. Vulnerable groups such as children and adolescents need special attention by health workers and policy makers. There is also a need for adherence indicators and interventions that are applicable in the setting of developing countries.

\section{Authors' Contribution}

Both authors have contributed equally to the manuscript. S. Biadgilign came up with the topic of the paper and involved in writing it. A. Reda developed the idea and involved in writing substantially. Both authors have reviewed and approved the final draft of the paper.

\section{References}

[1] United Nations Programme on HIV/AIDS, AIDS Epidemic Update, United Nations Programme on HIV/AIDS (UNAIDS) and World Health Organization (WHO), Geneva, Switzerland, 2009.

[2] B. H. Chi, R. A. Cantrell, I. Zulu et al., "Adherence to first-line antiretroviral therapy affects non-virologic outcomes among patients on treatment for more than 12 months in Lusaka, Zambia," International Journal of Epidemiology, vol. 38, no. 3, pp. 746-756, 2009.

[3] E. J. Mills, C. Bakanda, J. Birungi et al., "Life expectancy of persons receiving combination antiretroviral therapy in lowincome countries: a cohort analysis from Uganda," Annals of Internal Medicine, vol. 155, no. 4, pp. 209-217, 2011.

[4] WHO, "Towards universal access: scaling up priority HIV/AIDS interventions in the health sector: progress report 2010," In: WHO, editor. Geneva, Switzerland, WHO, 2010.

[5] J. B. Nachega, E. J. Mills, and M. Schechter, "Antiretroviral therapy adherence and retention in care in middle-income and low-income countries: current status of knowledge and research priorities," Current Opinion in HIV and AIDS, vol. 5, no. 1, pp. 70-77, 2010.

[6] G. H. Friedland and L. A. Andrews, "Adherence to antiretroviral therapy," AIDS Reviews, vol. 3, no. 3, pp. 111-120, 2001.

[7] G. M. Lucas, R. E. Chaisson, and R. D. Moore, "Highly active antiretroviral therapy in a large urban clinic: risk factors for virologic failure and adverse drug reactions," Annals of Internal Medicine, vol. 131, no. 2, pp. 81-87, 1999.

[8] A. M. J. Wensing, J. Vercauteren, D. A. Van De Vijver et al., "Transmission of drug-resistant HIV-1 in Europe remains limited to single classes," AIDS, vol. 22, no. 5, pp. 625-635, 2008.

[9] H. H. M. Truong, R. M. Grant, W. McFarland et al., "Routine surveillance for the detection of acute and recent HIV infections and transmission of antiretroviral resistance," AIDS, vol. 20, no. 17, pp. 2193-2197, 2006.

[10] R. J. Landovitz, "What's the best way to measure ART adherence?" Journal Watch, vol. 23, no. 3, 2011.

[11] R. C. Vreeman, S. E. Wiehe, E. C. Pearce, and W. M. Nyandiko, "A systematic review of pediatric adherence to antiretroviral 
therapy in low- and middle-income countries," Pediatric Infectious Disease Journal, vol. 27, no. 8, pp. 686-691, 2008.

[12] H. Liu, C. E. Golin, L. G. Miller et al., "A comparison study of multiple measures of adherence to HIV protease inhibitors," Annals of Internal Medicine, vol. 134, no. 10, pp. 968-977, 2001.

[13] P. T. Nieuwkerk and F. J. Oort, "Self-reported adherence to antiretroviral therapy for HIV-1 infection and virologic treatment response: a meta-analysis," Journal of Acquired Immune Deficiency Syndromes, vol. 38, no. 4, pp. 445-448, 2005.

[14] L. Osterberg and T. Blaschke, "Adherence to medication," New England Journal of Medicine, vol. 353, no. 5, pp. 487-497, 2005.

[15] M. A. Chesney, "The elusive gold standard: future perspectives for HIV adherence assessment and intervention," Journal of Acquired Immune Deficiency Syndromes, vol. 43, no. 1, pp. S149-S155, 2006.

[16] S. Biadgilign, A. A. Reda, A. Deribew et al., "Knowledge and attitudes of caregivers of HIV-infected children toward antiretroviral treatment in Ethiopia," Patient Education and Counseling, vol. 85, no. 2, pp. e89-e94, 2011.

[17] J. M. Simoni, A. Montgomery, E. Martin, M. New, P. A. Demas, and S. Rana, "Adherence to antiretroviral therapy for pediatric HIV infection: a qualitative systematic review with recommendations for research and clinical management," Pediatrics, vol. 119, no. 6, pp. e1371-e1383, 2007.

[18] A. D. Harries, D. S. Nyangulu, N. J. Hargreaves, O. Kaluwa, and F. M. Salaniponi, "Preventing antiretroviral anarchy in subSaharan Africa," The Lancet, vol. 358, no. 9279, pp. 410-414, 2001.

[19] C. Orrell, D. R. Bangsberg, M. Badri, and R. Wood, "Adherence is not a barrier to successful antiretroviral therapy in South Africa," AIDS, vol. 17, no. 9, pp. 1369-1375, 2003.

[20] E. J. Mills, J. B. Nachega, I. Buchan et al., "Adherence to antiretroviral therapy in sub-Saharan Africa and North America: a meta-analysis," Journal of the American Medical Association, vol. 296, no. 6, pp. 679-690, 2006.

[21] L. C. Ivers, D. Kendrick, and K. Doucette, "Efficacy of antiretroviral therapy programs in resource-poor settings: a meta-analysis of the published literature," Clinical Infectious Diseases, vol. 41, no. 2, pp. 217-224, 2005.

[22] C. A. Mellins, E. Brackis-Cott, C. Dolezal, and E. J. Abrams, "The role of psychosocial and family factors in adherence to antiretroviral treatment in human immunodeficiency virusinfected children," Pediatric Infectious Disease Journal, vol. 23, no. 11, pp. 1035-1041, 2004.

[23] J. Byakika-Tusiime, J. H. Oyugi, W. A. Tumwikirize, E. T. Katabira, P. N. Mugyenyi, and D. R. Bangsberg, "Adherence to HIV antiretroviral therapy in HIV+ Ugandan patients purchasing therapy," International Journal of STD and AIDS, vol. 16, no. 1, pp. 38-41, 2005.

[24] I. Lanièce, M. Ciss, A. Desclaux et al., "Adherence to HAART and its principal determinants in a cohort of Senegalese adults," AIDS, vol. 17, supplement 3, pp. S103-S108, 2003.

[25] J. T. Crane, A. Kawuma, J. H. Oyugi et al., "The price of adherence: qualitative findings from HIV positive individuals purchasing fixed-dose combination generic HIV antiretroviral therapy in Kampala, Uganda," AIDS and Behavior, vol. 10, no. 4, pp. 437-442, 2006.

[26] D. M. Gibb, R. L. Goodall, V. Giacomet, L. McGee, A. Compagnucci, and H. Lyall, "Adherence to prescribed antiretroviral therapy in human immunodeficiency virus-infected children in the PENTA 5 trial," Pediatric Infectious Disease Journal, vol. 22, no. 1, pp. 56-62, 2003.
[27] M. A. Chesney, "Factors affecting adherence to antiretroviral therapy," Clinical Infectious Diseases, vol. 30, no. 2, pp. S171S176, 2000.

[28] M. Byrne, J. Honig, A. Jurgrau, S. M. Heffernan, and M. C. Donahue, "Achieving adherence with antiretroviral medications for pediatric HIV disease," AIDS Reader, vol. 12, no. 4, pp. 151-164, 2002.

[29] M. G. Ferris and M. W. Kline, "Editorial comment: challenges to pediatric adherence to antiretroviral medications," AIDS Reader, vol. 12, no. 4, pp. 162-163, 2002.

[30] R. Lwin and D. Melin, "Pediatric HIV infection," Journal of Child Psychology and Psychiatry, vol. 42, pp. 427-438, 2001.

[31] P. J. Gavin and R. Yogev, "The role of protease inhibitor therapy in children with HIV infection," Pediatric Drugs, vol. 4, no. 9, pp. 581-607, 2002.

[32] C. A. Wedekind and D. Pugatch, "Lipodystrophy syndrome in children infected with human immunodeficiency virus," Pharmacotherapy, vol. 21, no. 7, pp. 861-866, 2001.

[33] L. Armistead, L. Tannenbaum, R. Forehand, E. Morse, and P. Morse, "Disclosing HIV status: are mothers telling their children?" Journal of Pediatric Psychology, vol. 26, no. 1, pp. 11-20, 2001.

[34] A. Reddi, S. C. Leeper, A. C. Grobler et al., "Preliminary outcomes of a paediatric highly active antiretroviral therapy cohort from KwaZulu-Natal, South Africa," BMC Pediatrics, vol. 7, p. 34, 2007.

[35] F. Bajunirwe, E. J. Arts, D. J. Tisch, C. H. King, S. M. Debanne, and A. K. Sethi, "Adherence and treatment response among HIV-1-infected adults receiving antiretroviral therapy in a rural government hospital in Southwestern Uganda," Journal of the International Association of Physicians in AIDS Care, vol. 8, no. 2, pp. 139-147, 2009.

[36] P. Sellier, P. Clevenbergh, L. Ljubicic et al., "Comparative evaluation of adherence to antiretroviral therapy in subSaharan African native HIV-infected patients in France and Africa," Clinical Infectious Diseases, vol. 43, no. 5, pp. 654-657, 2006.

[37] D. Nash, Y. Wu, B. Elul, D. Hoos, and W. El Sadr, "Programlevel and contextual-level determinants of low-median $\mathrm{CD}^{+}$ cell count in cohorts of persons initiating ART in eight subSaharan African countries," AIDS, vol. 25, no. 12, pp. 15231533, 2011.

[38] H. O. Ramadhani, N. M. Thielman, K. Z. Landman et al., "Predictors of incomplete adherence, virologic failure, and antiviral drug resistance among HIV-infected adults receiving antiretroviral therapy in Tanzania," Clinical Infectious Diseases, vol. 45, no. 11, pp. 1492-1498, 2007.

[39] G. L. Birbeck, E. Chomba, M. Kvalsund et al., "Antiretroviral adherence in rural zambia: the first year of treatment availability," American Journal of Tropical Medicine and Hygiene, vol. 80, no. 4, pp. 669-674, 2009.

[40] J. B. Nachega, D. M. Stein, D. A. Lehman et al., "Adherence to antiretroviral therapy in HIV-infected adults in Soweto, South Africa," AIDS Research and Human Retroviruses, vol. 20, no. 10, pp. 1053-1056, 2004.

[41] E. Pontali, "Facilitating adherence to highly active antiretroviral therapy in children with HIV infection: what are the issues and what can be done?" Pediatric Drugs, vol. 7, no. 3, pp. 137149, 2005.

[42] M. Skovdal, C. Campbell, K. Nhongo, C. Nyamukapa, and S. Gregson, "Contextual and psychosocial influences on antiretroviral therapy adherence in rural Zimbabwe: towards a systematic framework for programme planners," International 
Journal of Health Planning and Management, vol. 26, no. 3, pp. 296-318, 2011.

[43] A. Amberbir, K. Woldemichael, S. Getachew, B. Girma, and K. Deribe, "Predictors of adherence to antiretroviral therapy among HIV-infected persons: a prospective study in Southwest Ethiopia," BMC Public Health, vol. 8, p. 265, 2008.

[44] J. Byakika-Tusiime, J. Crane, J. H. Oyugi et al., "Longitudinal antiretroviral adherence in HIV+ Ugandan parents and their children initiating HAART in the MTCT-plus family treatment model: role of depression in declining adherence over time," AIDS and Behavior, vol. 13, no. 1, pp. S82-S91, 2009.

[45] R. G. Steele and D. Grauer, "Adherence to antiretroviral therapy for pediatric HIV infection: review of the literature and recommendations for research," Clinical Child and Family Psychology Review, vol. 6, no. 1, pp. 17-30, 2003.

[46] E. Kip, V. J. Ehlers, and D. M. Van Der Wal, "Patients adherence to anti-retroviral therapy in Botswana," Journal of Nursing Scholarship, vol. 41, no. 2, pp. 149-157, 2009.

[47] M. H. Watt, S. Maman, J. A. Earp et al., "It's all the time in my mind': facilitators of adherence to antiretroviral therapy in a Tanzanian setting," Social Science and Medicine, vol. 68, no. 10, pp. 1793-1800, 2009.

[48] R. A. Cantrell, M. Sinkala, K. Megazinni et al., "A pilot study of food supplementation to improve adherence to antiretroviral therapy among food-insecure adults in Lusaka, Zambia," Journal of Acquired Immune Deficiency Syndromes, vol. 49, no. 2, pp. 190-195, 2008.

[49] C. Serrano, R. Laporte, M. Ide et al., "Family nutritional support improves survival, immune restoration and adherence in HIV patients receiving ART in developing country," Asia Pacific Journal of Clinical Nutrition, vol. 19, no. 1, pp. 68-75, 2010.

[50] S. D. Weiser, K. Leiter, M. Heisler et al., "A population-based study on alcohol and high-risk sexual behaviors in Botswana," PLoS Medicine, vol. 3, no. 10, pp. 1940-1948, 2006.

[51] G. Chander, B. Lau, and R. D. Moore, "Hazardous alcohol use: a risk factor for non-adherence and lack of suppression in HIV infection," Journal of Acquired Immune Deficiency Syndromes, vol. 43, no. 4, pp. 411-417, 2006.

[52] R. S. Braithwaite, K. A. McGinnis, J. Conigliaro et al., "A temporal and dose-response association between alcohol consumption and medication adherence among veterans in care," Alcoholism Clinical and Experimental Research, vol. 29, no. 7, pp. 1190-1197, 2005.

[53] M. J. Stirratt, R. H. Remien, A. Smith, O. Q. Copeland, C. Dolezal, and D. Krieger, "The role of HIV serostatus disclosure in antiretroviral medication adherence," AIDS and Behavior, vol. 10, no. 5, pp. 483-493, 2006.

[54] C. J. Gill, D. H. Hamer, J. L. Simon, D. M. Thea, and L. L. Sabin, "No room for complacency about adherence to antiretroviral therapy in sub-Saharan Africa," AIDS, vol. 19, no. 12, pp. 1243-1249, 2005.

[55] C. S. Hendershot, S. A. Stoner, D. W. Pantalone, and J. M. Simoni, "Alcohol use and antiretroviral adherence: review and meta-analysis," Journal of Acquired Immune Deficiency Syndromes, vol. 52, no. 2, pp. 180-202, 2009.

[56] G. J. Domek, "Social consequences of antiretroviral therapy: preparing for the unexpected futures of HIV-positive children," The Lancet, vol. 367, no. 9519, pp. 1367-1369, 2006.

[57] B. S. Rachlis, E. J. Mills, and D. C. Cole, "Livelihood security and adherence to antiretroviral therapy in low and middle income settings: a systematic review," PLoS ONE, vol. 6, no. 5, Article ID e18948, 2011.
[58] S. Weiser, W. Wolfe, D. Bangsberg et al., "Barriers to Antiretroviral Adherence for Patients Living with HIV Infection and AIDS in Botswana," Journal of Acquired Immune Deficiency Syndromes, vol. 34, no. 3, pp. 281-288, 2003.

[59] A. P. Hardon, D. Akurut, C. Comoro et al., "Hunger, waiting time and transport costs: time to confront challenges to ART adherence in Africa," AIDS Care, vol. 19, no. 5, pp. 658-665, 2007.

[60] J. B. Nachega, A. R. Knowlton, A. Deluca et al., "Treatment supporter to improve adherence to antiretroviral therapy in HIV-infected South African adults: a qualitative study," Journal of Acquired Immune Deficiency Syndromes, vol. 43, no. 1, pp. S127-S133, 2006.

[61] N. Sanjobo, J. C. Frich, and A. Fretheim, "Barriers and facilitators to patients' adherence to antiretroviral treatment in Zambia: a qualitative study," Sahara Journal, vol. 5, no. 3, pp. 136-143, 2008.

[62] G. H. Mshana, J. Wamoyi, J. Busza et al., "Barriers to accessing antiretroviral therapy in Kisesa, Tanzania: a qualitative study of early rural referrals to the national program," AIDS Patient Care and STDs, vol. 20, no. 9, pp. 649-657, 2006.

[63] D. M. Tuller, D. R. Bangsberg, J. Senkungu, N. C. Ware, N. Emenyonu, and S. D. Weiser, "Transportation costs impede sustained adherence and access to HAART in a clinic population in Southwestern Uganda: a qualitative study," AIDS and Behavior, vol. 14, no. 4, pp. 778-784, 2010.

[64] C. Orrell, "Antiretroviral adherence in a resource-poor setting," Current HIV/AIDS Reports, vol. 2, no. 4, pp. 171-176, 2005.

[65] N. C. Ware, J. Idoko, S. Kaaya et al., "Explaining adherence success in sub-Saharan Africa: an ethnographic study," PLoS Medicine, vol. 6, no. 1, Article ID e1000011, pp. 0039-0047, 2009.

[66] M. Mukhtar-Yola, S. Adeleke, D. Gwarzo, and Z. F. Ladan, "Preliminary investigation of adherence to antiretroviral therapy among children in Aminu Kano Teaching Hospital, Nigeria," African Journal of AIDS Research, vol. 5, no. 2, pp. 141-144, 2006.

[67] R. B. Van Dyke, S. Lee, G. M. Johnson et al., "Reported adherence as a determinant of response to highly active antiretroviral therapy in children who have human immunodeficiency virus infection," Pediatrics, vol. 109, no. 4, p. e61, 2002.

[68] E. Grant, D. Logie, M. Masura, D. Gorman, and S. A. Murray, "Factors facilitating and challenging access and adherence to antiretroviral therapy in a township in the Zambian Copperbelt: a qualitative study," AIDS Care, vol. 20, no. 10, pp. 1155-1160, 2008.

[69] J. S. Mukherjee, L. Ivers, F. Leandre, P. Farmer, and H. Behforouz, "Antiretroviral therapy in resource-poor settings: decreasing barriers to access and promoting adherence," Journal of Acquired Immune Deficiency Syndromes, vol. 43, no. 1, pp. S123-S126, 2006.

[70] G. Meyer-Rath and M. Richter, "User fees, transport costs, and the ethics of exemption: how free is free art?" Southern African Journal of HIV Medicine, no. 27, pp. 52-56, 2007.

[71] J. B. Nachega, R. Leisegang, D. Bishai et al., "Association of antiretroviral therapy adherence and health care costs," Annals of Internal Medicine, vol. 152, no. 1, pp. 18-25, 2010.

[72] D. R. Bangsberg, "Preventing HIV antiretroviral resistance through better monitoring of treatment adherence," Journal of Infectious Diseases, vol. 197, no. 3, pp. S272-S278, 2008.

[73] J. M. Simoni, K. R. Amico, C. R. Pearson, and R. Malow, "Strategies for promoting adherence to antiretroviral therapy: 
a review of the literature," Current Infectious Disease Reports, vol. 10, no. 6, pp. 515-521, 2008.

[74] K. R. Amico, J. J. Harman, and B. T. Johnson, "Efficacy of antiretroviral therapy adherence interventions: a research synthesis of trials, 1996 to 2004," Journal of Acquired Immune Deficiency Syndromes, vol. 41, no. 3, pp. 285-297, 2006.

[75] A. C. Collier, H. Ribaudo, A. L. Mukherjee, J. Feinberg, M. A. Fischl, and M. Chesney, "A randomized study of serial telephone call support to increase adherence and thereby improve virologic outcome in persons initiating antiretroviral therapy," Journal of Infectious Diseases, vol. 192, no. 8, pp. 1398-1406, 2005.

[76] H. P. McDonald, A. X. Garg, and R. B. Haynes, "Interventions to enhance patient adherence to medication prescriptions: scientific review," Journal of the American Medical Association, vol. 288, no. 22, pp. 2868-2879, 2002.

[77] S. Rueda, L. Y. Park-Wyllie, A. M. Bayoumi et al., "Patient support and education for promoting adherence to highly active antiretroviral therapy for HIV/AIDS," Cochrane Database of Systematic Reviews, vol. 3, p. CD001442, 2006.

[78] A. K. Gusdal, C. Obua, T. Andualem, R. Wahlstrom, J. Chalker, and G. Fochsen, "Peer counselors' role in supporting patients' adherence to ART in Ethiopia and Uganda," AIDS Care, vol. 23, no. 6, pp. 657-662, 2011.

[79] M. Skovdal, C. Campbell, C. Madanhire, C. Nyamukapa, and S. Gregson, "Challenges faced by elderly guardians in sustaining the adherence to antiretroviral therapy in HIVinfected children in Zimbabwe," AIDS Care, vol. 23, no. 8, pp. 957-964, 2011.

[80] S. Rosen, M. P. Fox, and C. J. Gill, "Patient retention in antiretroviral therapy programs in sub-Saharan Africa: a systematic review," PLoS Medicine, vol. 4, no. 10, pp. 16911701, 2007.

[81] K. M. Berg and J. H. Arnsten, "Practical and conceptual challenges in measuring antiretroviral adherence," Journal of Acquired Immune Deficiency Syndromes, vol. 43, no. 1, pp. S79S87, 2006.

[82] G. Wagner and L. G. Miller, "Is the Influence of Social Desirability on Patients' Self-Reported Adherence Overrated? [1]," Journal of Acquired Immune Deficiency Syndromes, vol. 35, no. 2, pp. 203-204, 2004.

[83] J. Chalker, A. Wagner, G. Tomson et al., "Urgent need for coordination in adopting standardized antiretroviral adherence performance indicators," Journal of Acquired Immune Deficiency Syndromes, vol. 53, no. 2, pp. 159-161, 2010. 


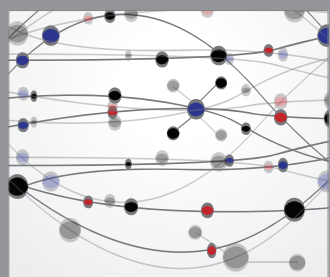

The Scientific World Journal
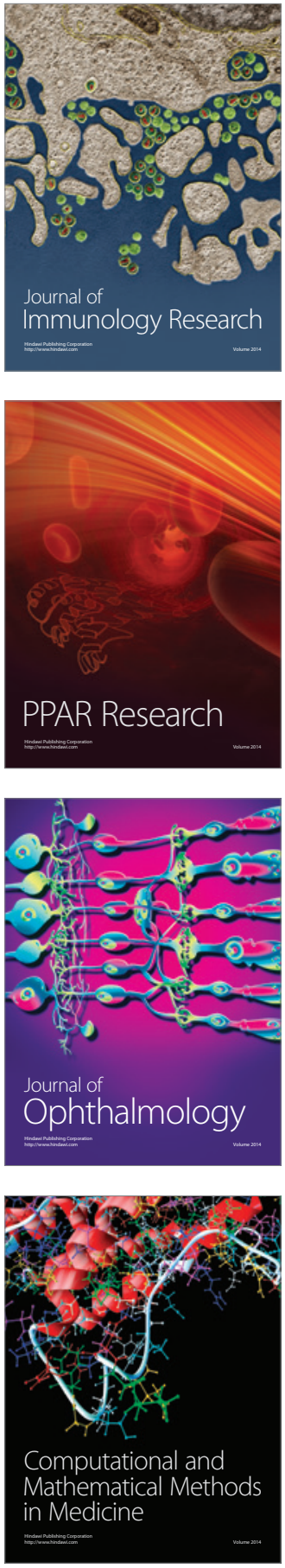

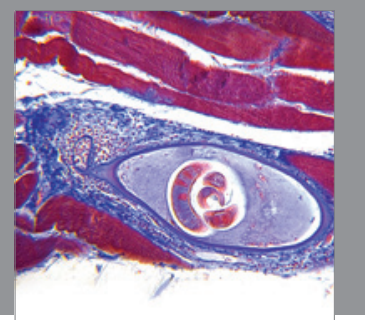

Gastroenterology

Research and Practice
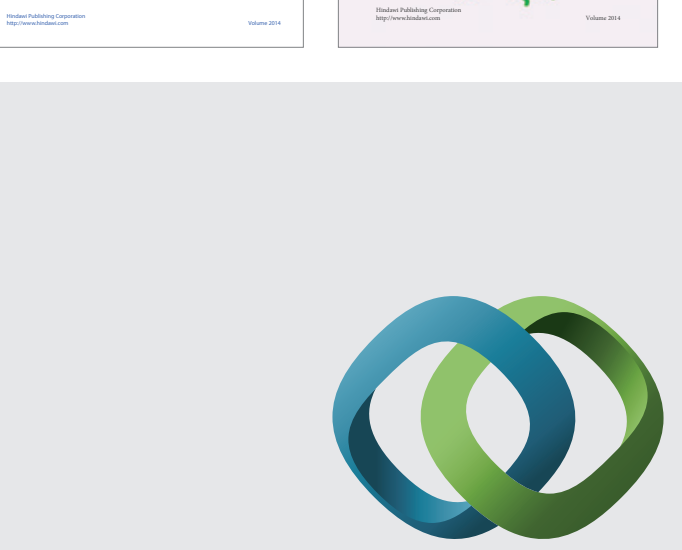

\section{Hindawi}

Submit your manuscripts at

http://www.hindawi.com
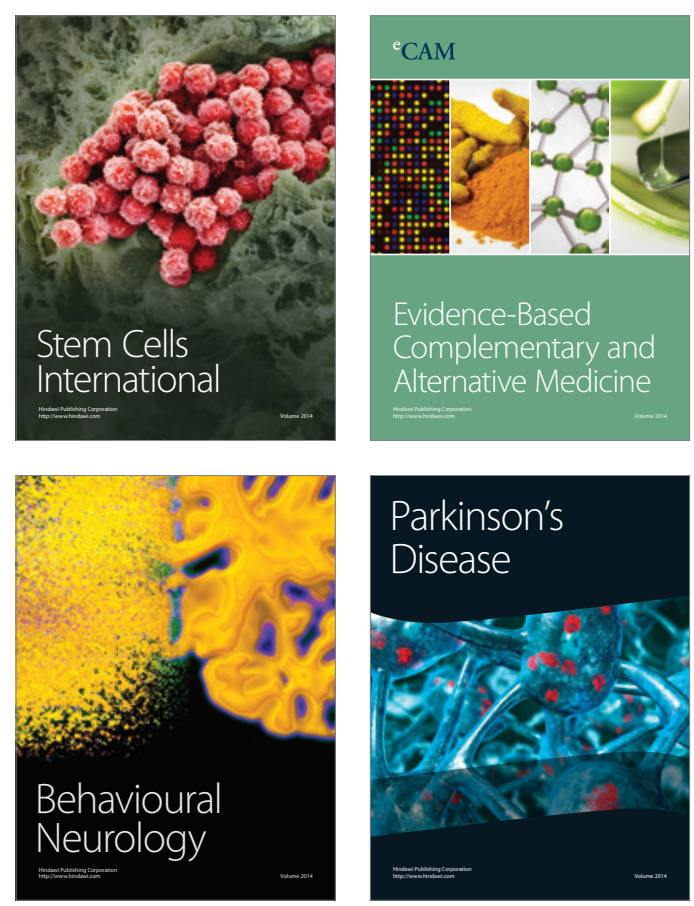

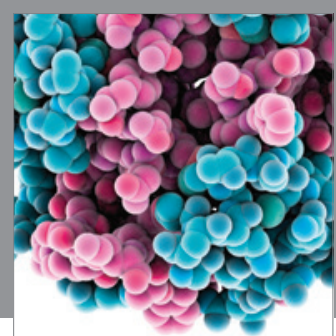

Journal of
Diabetes Research

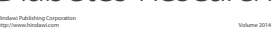

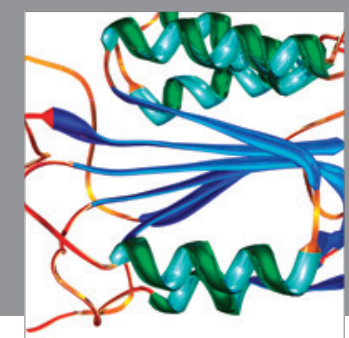

Disease Markers
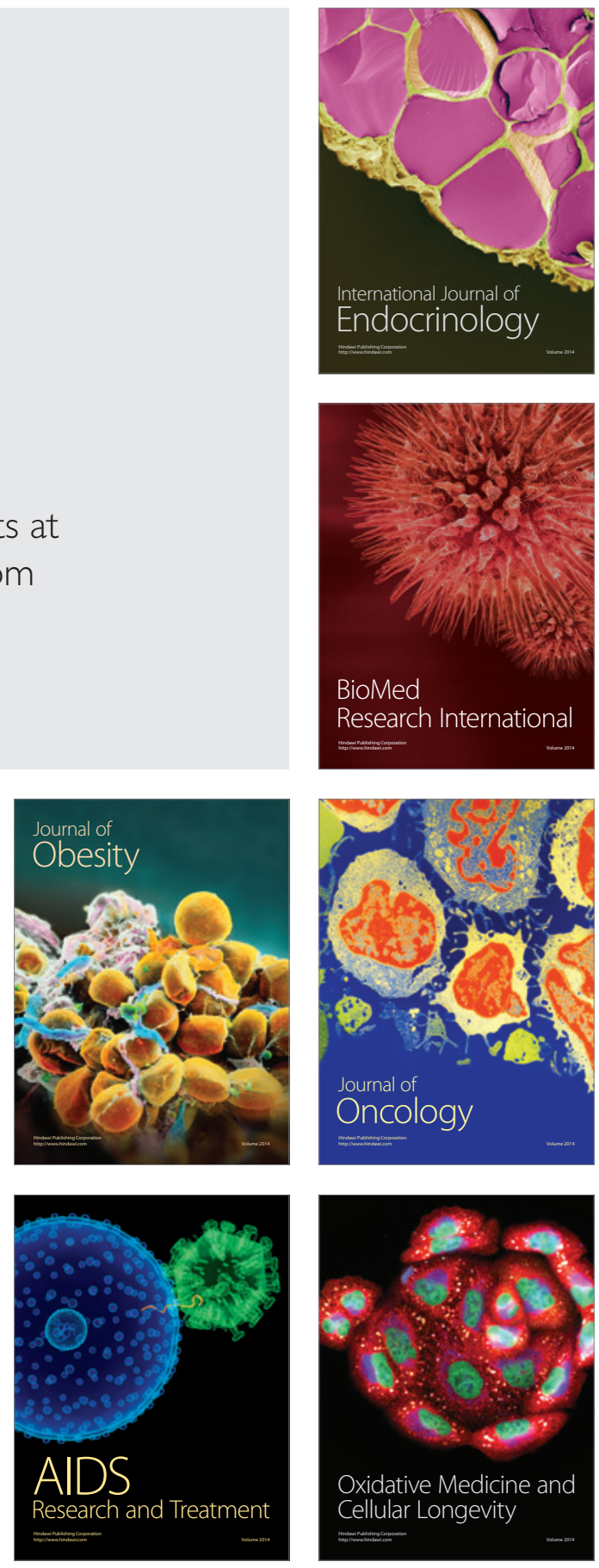